\title{
Effect of Tailings Fine Content on the Properties of Cemented Paste Backfill from the Perspective Packing Density
}

\author{
Haijun Wang, ${ }^{1,2}$ Xiaogang Sun $\mathbb{D}^{2},{ }^{2}$ Jianwen Wang, ${ }^{1}$ Yun Duan, ${ }^{1}$ Changsuo Zhang, \\ Jingping Qiu, ${ }^{2}$ and Zhenbang Guo $\mathbb{D}^{2}$ \\ ${ }^{1}$ BGRIMM Technology Group, Beijing 100160, China \\ ${ }^{2}$ School of Resource and Civil Engineering, Northeastern University, Shenyang 110819, China \\ Correspondence should be addressed to Xiaogang Sun; sunxiaogang@mail.neu.edu.cn
}

Received 28 March 2021; Accepted 24 May 2021; Published 2 June 2021

Academic Editor: Tingting Zhang

Copyright (C) 2021 Haijun Wang et al. This is an open access article distributed under the Creative Commons Attribution License, which permits unrestricted use, distribution, and reproduction in any medium, provided the original work is properly cited.

In order to quantitatively study the influence of tailings fine content on the properties of cemented paste backfill (CPB) and further understand the mechanism of tailings fine content acting, the concept of packing density was introduced in this study. The packing density of each tailings sample was measured by the wet packing method after the samples with various fine contents were prepared. Moreover, CPBs with different tailings fine contents were tested by the mini slump test, rheological test, uniaxial compressive strength (UCS) test, and mercury intrusion porosimetry test. The results demonstrated that the flow spread and UCS both increase first and then decrease with the increase of tailings fine content, while the yield stress shows an opposite trend. The fine content of tailings affects the flowability of fresh CPB mainly through the packing density. When the fine content is high, the influence of the specific surface area of tailings cannot be ignored. The packing density is an important factor affecting the strength of $\mathrm{CPB}$, and there is an obvious linear relationship between the packing density and UCS. The pore structure of CPB samples with different tailing fine contents is significantly different, and the macroscopic packing density changes the strength of CPB by affecting the microscopic pores.

\section{Introduction}

Mining activities will inevitably have adverse effects on the environment, such as the generation of solid wastes (tailings and coal gangue) and geological disasters such as surface collapse and dam failure of tailings ponds [1-5]. Cemented paste backfill (CPB) technology has become one of the most effective methods to solve these problems in underground mining [6-9]. Its advantages include effective utilization of tailings waste, thus reducing the tailings disposal on the surface, alleviating the surface subsidence during underground mining, and reducing ore loss and dilution [10-12]. CPB is generally composed of tailings, cementitious materials, and mixing water [13-15]. The cementitious material is generally ordinary Portland cement (OPC), which aims to make CPB gain strength to support the surface after a certain curing age [16-19]. Since the backfill cost mainly comes from cementitious materials, it has become a trend to mix OPC with solid wastes such as blast furnace slag and fly ash [20-27]. The solid content of CPB slurry is generally $70-85 \%$, so as to achieve the desired consistency and make the slurry transported to the stope smoothly [28-30].

It is worth noting that tailings are the main components of the $\mathrm{CPB}$, accounting for more than $66 \%$ of the mass [31]. This means that the properties of tailings cannot be ignored for CPB. Xiapeng et al. [32] studied the effect of initial sulphate content on the rheological properties of $\mathrm{CPB}$. They found that with the increase of initial sulphate concentration, the yield stress decreases continuously, but the apparent viscosity shows an opposite trend. Li and Fall [33] explored the effect of the sulphate effect on the early strength of $\mathrm{CPB}$. They reported that sulphate is not conducive to the increase of $\mathrm{CPB}$ strength in the early age. Fall et al. [2] concluded that the increase of tailings density will lead to the increase of cementitious material consumption, so it is beneficial to the increase of CPB strength. Qi et al. [34] 
predicted the uniaxial compressive strength (UCS) of CPB by using the coupling model of boosted regression trees (BRT) and particle swarm optimization (PSO) and carried out sensitivity analysis on the influencing factors of the UCS. They believed that the influence of chemical composition of tailings cannot be ignored.

In addition to sulphate content and density, tailings particle size is also an important factor affecting CPB properties. Ke et al. [35] studied the effect of tailings fineness on the development of pore structure of CPB. The results show that the critical pore diameter and large pores decreased with the increase of tailings fineness. Deng et al. [36] observed that the $\mathrm{CPB}$ samples with finer particle sizes display a higher yield stress compared to the samples with coarser tailings particle sizes. On the basis of laboratory experiments and numerical simulation, Yang et al. believes that the cemented superfine unclassified tailings backfill prepared by reasonable mix proportion can achieve the function of subsidence control [10]. Cheng et al. studied [37] the effect of tailing particle gradation on the yield stress of fresh CPB. They concluded that particle gradation changed yield stress by affecting skeleton structure and pore structure. To sum up, tailings gradation has a significant impact on the performance of fresh or hardened $\mathrm{CPB}$, and these studies have made significant contributions to understanding of the influence of tailings characteristics on CPB properties. However, on the other hand, there are few reports on the quantitative research on the influence of tailings grading, and the mechanism of tailings grading on flowability and UCS of CPB is also few. This is undoubtedly an obstacle to understanding the properties of CPB. Although Qiu et al. introduced the index of water film thickness (WFT) to quantify the influence of tailings fineness, the tailings sample does not contain coarse tailings [38]. Furthermore, rheological properties were not involved in the study of Qiu et al. [37, 39]. Therefore, it is necessary to further explore the influence of tailings particle size on CPB properties.

Based on the above discussion, the concept of packing density of tailing particles was introduced to quantify the influence of tailing particle size. After preparing tailings samples with different fine contents $(<20 \mathrm{~m})$, a series of related experiments were carried out, such as the mini slump test, rheological test, UCS test, mercury intrusion porosimetry (MIP) test, and so on. Moreover, because tailings particles are generally fine, the dry packing method often has great limitations in measuring tailings packing density, so the wet packing method was adopted to measure packing density. The purpose of this study is to further understand the influence of tailings fine content on CPB properties and to provide theoretical basis for the design of mine backfill mix.

\section{Experimental}

2.1. Materials. In order to obtain tailings samples with different fine contents, the tailings from an iron mine in Liaoning Province, China, were adopted as the original material. The XQM-2 planetary ball mill was used for grinding at different times, and five tailings samples with different fine contents were obtained, which were $22.08 \%$, $31.51 \%, 42.20 \%, 51.63$, and $62.94 \%$, respectively. The particle size distribution of tailings samples with various fine contents is shown in Figure 1. The main chemical components of tailings include $\mathrm{SiO}_{2}, \mathrm{Fe}_{2} \mathrm{O}_{3}$, and $\mathrm{Al}_{2} \mathrm{O}_{3}$, and their mass percentages are $65.3 \%, 15.52 \%$, and $2.89 \%$ respectively. The commercial OPC (namely, PO42.5R) generally used in mines in China was adopted, the specific surface area is $5808 \mathrm{~cm}^{2} / \mathrm{g}$, and the specific gravity is 3.3 . The main physical and chemical properties of tailings and cement are given in Table 1. Furthermore, tap water was used as mixing water to obtain a fresh CPB slurry of desired consistency [26]. Detailed information on tap water can be found in [38].

2.2. Experimental Program. The main purpose of this study is to study the influence of the fine content of tailings on the properties of fresh or hardened CPB, so other factors remain unchanged. The binder dosage and solid content are fixed at $8 \%$ and $72 \%$, respectively, which are calculated from the following equations (equations (1) and (2)). In addition, the specific test scheme is given in Table 2.

$$
\begin{aligned}
\mathrm{BD}_{w \%} & =100 * \frac{M_{\text {binder }}}{M_{\text {tailings }}}, \\
\mathrm{SC}_{w \%} & =100 * \frac{M_{\text {tailings }}+M_{\text {binder }}}{M_{\text {tailings }}+M_{\text {binder }}+M_{\text {water }}},
\end{aligned}
$$

where $\mathrm{BD}_{w \%}$ is the binder dosage, $\mathrm{SC}_{w \%}$ is the solid content, and $M_{\text {binder }}, M_{\text {tailings }}$, and $M_{\text {water }}$ represent the mass of dry binder, dry tailings, and water in the $\mathrm{CPB}$, respectively.

2.3. Testing Procedures. In this study, the wet packing method was used to measure the packing density of tailings. Detailed experimental procedures are given in [40]. The research results of Qiu et al. [38, 39, 41] showed the rationality of using the wet packing method to measure the density of tailings. The tailings and OPC were weighed according to a preset proportion, poured into a stirring container, and then mixed at a low speed for 1 minute to make the dry materials evenly mixed.

Once the dry materials were mixed evenly, different amounts of water (shown as various water-solid ratios in the abscissa of Figure 2) were added to the solid particle system. After fully stirring evenly, fresh slurry was poured into a cylindrical container with a diameter and height of $10 \mathrm{~cm}$ to measure the packing density. When the water content is low, the concentration of the mixed system increases with the increase of water content due to the effect of liquid bridge $[42,43]$. When the water content exceeds a certain threshold, the concentration of the system decreases continuously if the water content continues to increase. Therefore, there is a threshold water content, at which time the system concentration reaches the maximum, and the maximum solid concentration can be regarded as the particle packing density. The concentration of the system can be obtained according to the following formulas: 


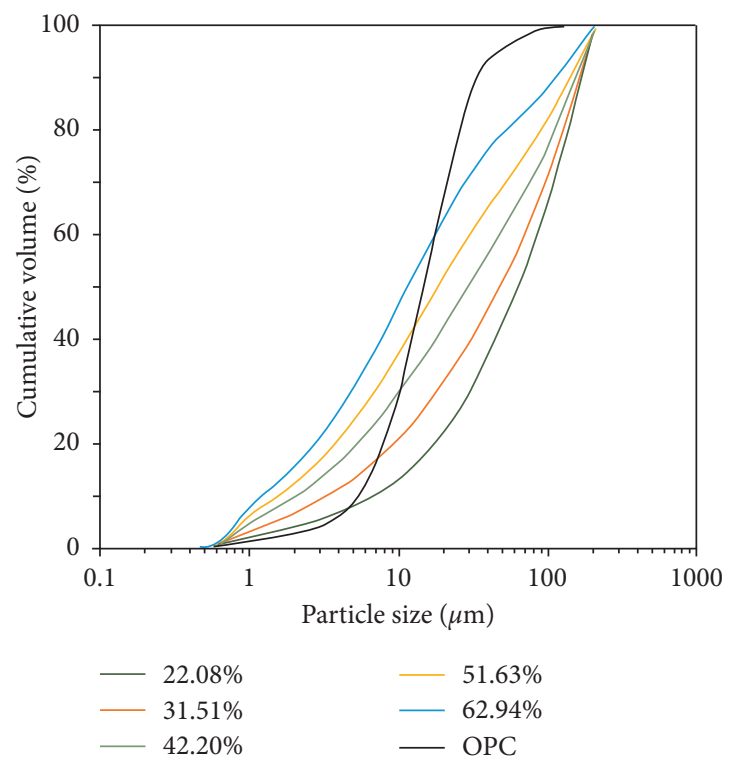

FIGURE 1: Particle size distribution of tailings and OPC.

TABLE 1: Main chemical and physical properties of OPC and tailings.

\begin{tabular}{|c|c|c|c|c|c|}
\hline Physical properties & $\mathrm{OPC}$ & Tailings & Chemical composition (\%) & $\mathrm{OPC}$ & Tailings \\
\hline Specific gravity & 3.3 & 3.02 & $\mathrm{SiO}_{2}$ & 21.43 & 65.3 \\
\hline \multirow[t]{5}{*}{$<20 \mu \mathrm{m}(\%)$} & 66.3 & 22.08 & $\mathrm{CaO}$ & 62.34 & 3.01 \\
\hline & & 31.51 & & & \\
\hline & & 42.20 & & & \\
\hline & & 51.63 & & & \\
\hline & & 62.94 & & & \\
\hline \multirow[t]{5}{*}{$D_{10}(\mu \mathrm{m})$} & 5.23 & 6.79 & $\mathrm{Fe}_{2} \mathrm{O}_{3}$ & 5.06 & 15.52 \\
\hline & & 3.35 & & & \\
\hline & & 2.08 & & & \\
\hline & & 1.75 & & & \\
\hline & & 1.24 & & & \\
\hline \multirow[t]{5}{*}{$D_{30}(\mu \mathrm{m})$} & 10.18 & 30.13 & $\mathrm{Al}_{2} \mathrm{O}_{3}$ & 4.25 & 2.89 \\
\hline & & 18.35 & & & \\
\hline & & 10.28 & & & \\
\hline & & 6.95 & & & \\
\hline & & 4.89 & & & \\
\hline \multirow[t]{5}{*}{$D_{60}(\mu \mathrm{m})$} & 17.8 & 86.23 & $\mathrm{MgO}$ & 2.61 & 0.58 \\
\hline & & 70.59 & & & \\
\hline & & 45.54 & & & \\
\hline & & 30.35 & & & \\
\hline & & 17.57 & & & \\
\hline \multirow[t]{5}{*}{ Coefficient of uniformity } & 3.36 & 12.69 & $\mathrm{Na}_{2} \mathrm{O}$ & 0.41 & 2.88 \\
\hline & & 21.05 & & & \\
\hline & & 23.33 & & & \\
\hline & & 17.39 & & & \\
\hline & & 14.18 & & & \\
\hline \multirow[t]{5}{*}{ Coefficient of curvature } & 1.1 & 1.55 & $\mathrm{~K}_{2} \mathrm{O}$ & 0.73 & 8.76 \\
\hline & & 1.42 & & & \\
\hline & & 1.05 & & & \\
\hline & & 0.91 & & & \\
\hline & & 1.10 & & & \\
\hline- & - & - & $\mathrm{SO}_{3}$ & 1.48 & 0.32 \\
\hline
\end{tabular}

Coefficient of uniformity $=D_{60} / D_{10}$; coefficient of curvature $=\left(D_{30}\right)^{2} /\left(D_{10} \times D_{60}\right)$. 
TABLE 2: Experimental program.

\begin{tabular}{lcc}
\hline Binder dosage (\%) & Solid content (\%) & Fine content (\%) \\
\hline 8 & 72 & 22.9 \\
& & 28.2 \\
& 37.3 \\
& 46.9 \\
& 59.8 \\
\hline
\end{tabular}

$$
\begin{aligned}
& u=\frac{V-V_{s}}{V_{s}}, \\
& \varnothing=\frac{V_{s}}{V},
\end{aligned}
$$

where $V$ and $V_{s}$ represent the volume of the cylindrical container and the volume of the solid particles in slurry, respectively. $\varnothing$ is the solid concentration of the system with various water contents. $u$ is the voids ratio. It is worth noting that the voids ratio and solid concentration satisfy the following relationship:

$$
\varnothing=\frac{1}{1+u} .
$$

Due to the fine tailing particles, the mini slump cone was used to measure the flow spread of fresh CPB slurry and characterize the flowability of slurry. The top diameter of the mini slump cone is $5 \mathrm{~cm}$, the bottom diameter is $10 \mathrm{~cm}$, and the height is $15 \mathrm{~cm}$. Detailed information on mini slump and mini slump test procedures can be found in [39].

The rheological properties of fresh $\mathrm{CPB}$ were tested by the Brookfield RSR-SST rheometer. A four-bladed vane with a diameter of $20 \mathrm{~mm}$ and a height of $40 \mathrm{~mm}$ was selected in this study [44]. Once the CPB mixture was ready, it is quickly poured into the sample cup of the rheometer. To ensure that all fresh CPB samples are at a reproducible reference state, preshear progress is performed before each rheological test [45]. During the preshear, a shear rate of $100 \mathrm{~s}^{-1}$ is selected for a duration of $1 \mathrm{~min}$. Subsequently, the shear rate decreases from $100 \mathrm{~s}^{-1}$ to $0.003 \mathrm{~s}^{-1}$ within 1 minute (Figure 3), and the data recorded during this stage were used to fit the rheological model [46]. Based on the experimental results, the correlation coefficients $R^{2}$ obtained by fitting the Bingham model (equation (5)) are all over 0.98 , so it is reasonable to select this model to obtain the rheological parameters of $\mathrm{CPB}$.

$$
\tau=\tau_{0}+\eta \cdot \gamma,
$$

where $\tau$ represents the shear stress $(\mathrm{Pa}) ; \tau_{0}$ and $\eta$ represent the yield stress $(\mathrm{Pa})$ and plastic viscosity $(\mathrm{Pa} \cdot \mathrm{s})$, respectively; $\gamma$ is the shear rate $\left(\mathrm{s}^{-1}\right)$.

The Humboldt HM-5030 with loading capacity of $50 \mathrm{kN}$ was used to determine the UCS of the CPB. The loading method adopted the displacement loading, and the specific loading rate was $1 \mathrm{~mm} / \mathrm{min}$ [24]. After the UCS test, a small piece was selected to soak in isopropanol for 24 hours to stop hydration, then vacuum dry to constant weight, and perform the MIP test. A mercury porosimeter of AutoPore IV 9510 was used for pore measurement in this study. This

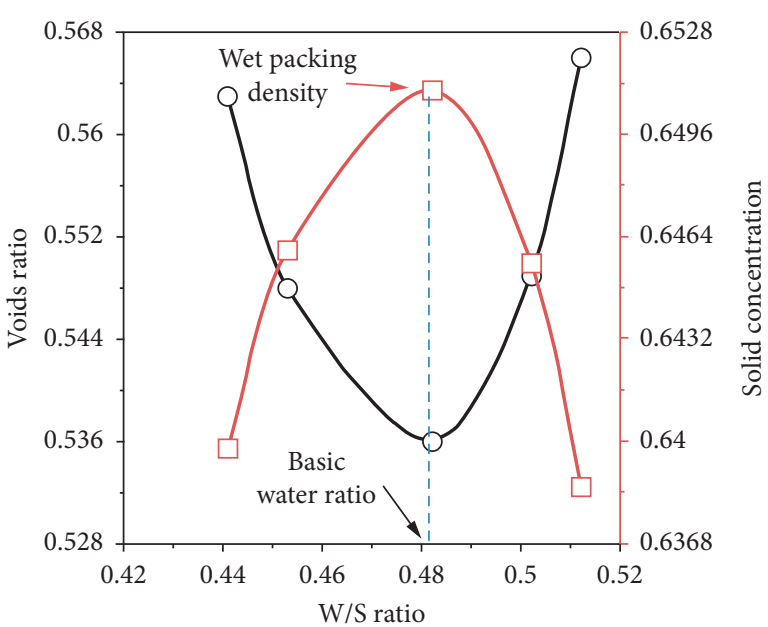

FIGURE 2: Wet packing test results for tailings.

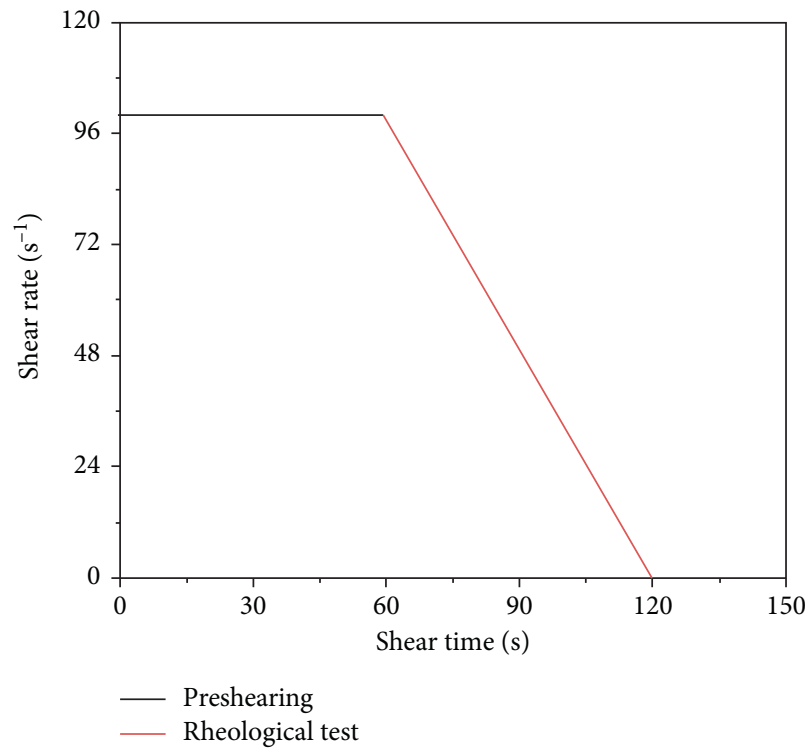

Figure 3: Applied rheological protocol.

instrument can achieve a maximum pressure of $414 \mathrm{MPa}$, and the measurable pore diameter range is $0.003-1000 \mu \mathrm{m}$.

It is worth noting that for the accuracy and reproducibility of the experimental results, each proportion of the sample is tested three times.

\section{Results and Discussion}

3.1. Effect of Tailings Fine Content on Packing Density. Figure 2 shows the effect of water-solid (W/S) ratio on voids ratio and solid concentration (only sample with fine content of $42.20 \%$ is listed here, and other results are similar). It can be clearly seen from the figure that when the W/S ratio is less than the basic water ratio (also known as the optimal watersolid ratio, and the corresponding solid concentration is the wet packing density), the solid concentration increases with the increase of the W/S ratio. This is because the amount of water mixed at this time is not enough to fill all the voids 
among the particles, and the formation of liquid bridges will reduce the particle spacing [40]. When the W/S ratio is greater than the basic water ratio, the suspension is formed and the tailings particles can be considered to be in a completely dispersed state [47]. Therefore, as the W/S ratio increases, the solid concentration gradually decreases. However, it should be noted that the basic water ratio is not necessarily equal to the minimum voids ratio. This is because when the minimum voids ratio occurs, there may be air trapped in the voids, resulting in a nonzero air proportion, as evidenced by the experimental results in the figure. Kwan et al. [47] also observed similar results when studying the wet packing density of concrete aggregates. Therefore, the basic water ratio should not be misunderstood as the minimum water ratio required to fill the voids among solid particles.

The variation of the packing density of the tailings particle system with different tailings fine contents under the wet and dry packing methods is shown in Figure 4. The packing density obtained by the dry packing method is in the range of $0.578-0.633$, while that obtained by the wet packing method is in 0.585-0.651. Comparing the experimental results of the packing density under dry and wet conditions, it can be found that regardless of the fine content, the results obtained by the wet packing method are significantly greater than that obtained by the dry packing method, which indicates that the effect of water has a significant effect on the packing density of the tailings. This is because the tailing particles are fine, and the strong interparticle interaction forces (electrostatic force and van der Waals force) lead to the tailing particles attracting each other to form aggregates, thus resulting in loose packing [48]. In the dry packing test, this strong interaction cannot be eliminated, but the effect can be weakened to some extent by the action of water, so that the aggregates are dispersed and the particles are packed tightly [47]. This is the main reason why the dry packing method generally underestimates the packing density of fine particle systems. However, it is noteworthy that in the coarse particle system, because the interparticle forces are relatively small, the dry packing method can also achieve accurate results.

On the other hand, we can notice that with the increase of tailings fine content, the packing density increases sharply at first and then decreases slowly. According to the particle packing theory [39], when the fine content is less than $42.20 \%$, the tailings are relatively coarse at this time. As the content of fine particles increases, the fine particles continue to fill the voids among the coarse particles, resulting in a significant increase in the overall packing density. This effect is called the filling effect of fine particles [39]. The increase of particle size distribution width may also be an important reason [49]. When the fine content is greater than $42.20 \%$, the voids among the coarse particles have been basically filled at this time. If the fine content of the tailings is further increased, the fine tailings will pull apart the coarse tailings, which is the so-called "wedge effect" [50]. Moreover, coarse particles act as a wall, and fine particles adhere to the wall surface, which further increases the voids volume, the socalled "wall effect" [51]. To sum up, when the tailing fine content ranges from $22.08 \%$ to $62.94 \%$, there exists an

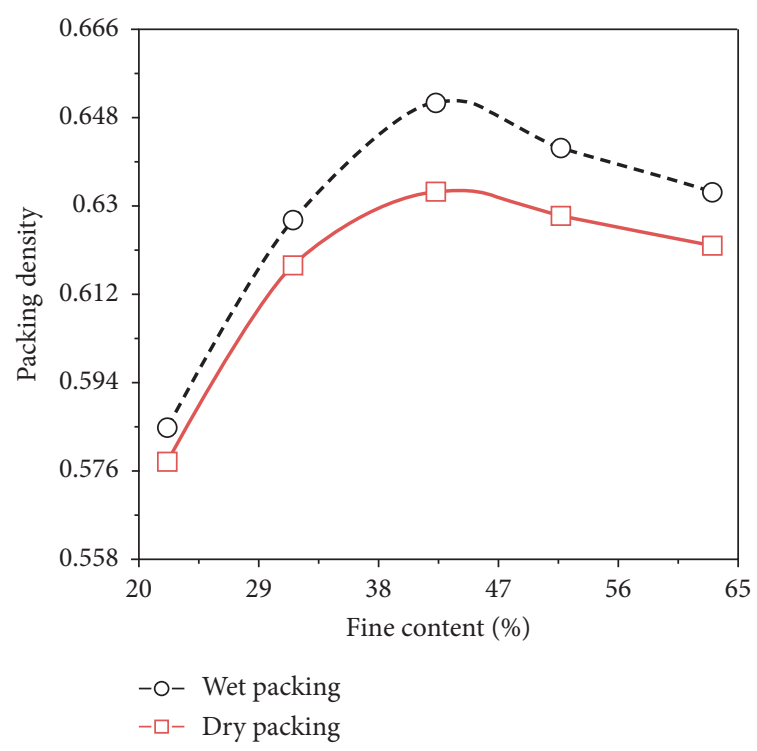

FIGURE 4: Results of the packing density measured by different methods.

optimal tailing fine content ( $42.20 \%$ in this study), which makes the packing density of the tailing particle system maximum.

3.2. Effect of Tailings Fine Content on Flow Spread. Figure 5 shows the variation of the flow spread of fresh CPB slurry under different tailings fine contents (solid content is fixed at $72 \%$ ). It is obvious from the figure that the flowability of $\mathrm{CPB}$ with various tailings fine contents is significantly different. When the fine content increases from $22.08 \%$ to $42.2 \%$, the flow spread increases. However, when the fine content changes from $42.2 \%$ to $62.94 \%$, the flow spread of fresh CPB slurry decreases significantly. The variation trend of flow spread with tailings fine content is similar to that of packing density with tailings fine content, which indicates that packing density affects the flowability of $\mathrm{CPB}$ slurry to a certain extent.

It is worth noting that when the coordinate system is established based on packing density and flow spread, the data points are very discrete and no obvious functional relationship appears (Figure 6). This shows that it is not comprehensive to study the flowability of CPB slurry only considering the factor of packing density. In other words, there are other important factors that affect the flowability of CPB. Qiu et al. [39] concluded that the specific surface area of tailings is also an important factor affecting the flow properties of fresh CPB slurry. When the fine content of tailings is between $22.08 \%$ and $42.2 \%$, the influence of packing density on the flowability of CPB slurry is dominant. When the solid content is constant, the larger the packing density means that there is more water left after filling the particle voids, thus the greater the thickness of the water film formed on the particle surface and the smaller the friction resistance, thus improving the flow performance [52]. However, when the tailings fine content is between $42.2 \%$ and $62.94 \%$, the influence of specific surface area of tailings 


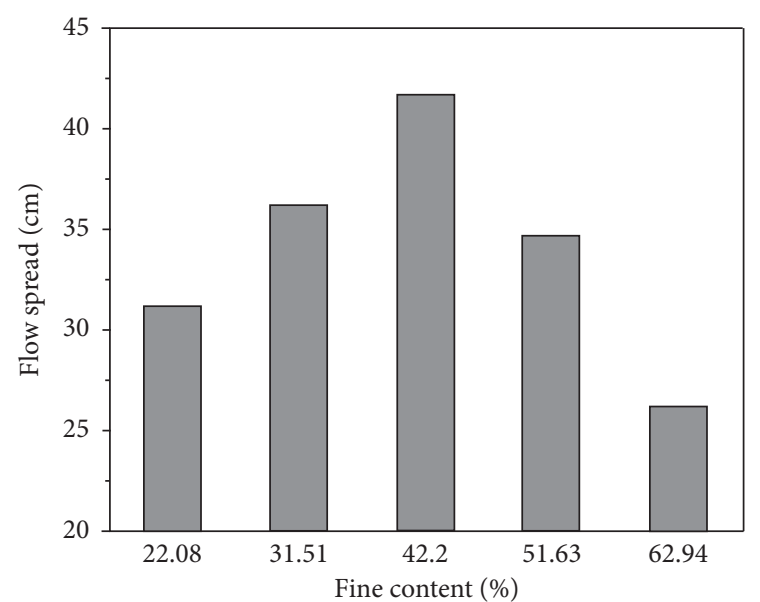

FIgURE 5: Flow spread variation with fine contents.

cannot be ignored. On the one hand, the packing density is reduced, which means that there is less water available to form the water film. On the other hand, the specific surface area of tailings also increases sharply. Therefore, under the coupling action of packing density and specific surface area, the flowability of $\mathrm{CPB}$ decreases significantly in this range [39]. To sum up, it can be inferred that when solid content remains constant, if the packing density and specific surface area of tailings are coupled into a new index, the index will have a good function relationship with the flow spread of fresh CPB slurry. Of course, water content is also an important factor affecting slurry flow performance and generally not fixed. In this case, a comprehensive index including water content, particle packing density, and specific surface area must be the key to predict the flowability of CPB. The results of Guo et al. [41] and Kwan and Li [53] also prove this view.

3.3. Effect of Tailings Fine Content on Yield Stress. The yield stress of the fresh CPB slurry varies with the fine content of tailings as shown in Figure 7. Obviously, with the increase of tailings fine content, the yield stress decreases first and then increases. The reason for this phenomenon may be that the fine content of tailings changes the packing density of particles, thus affecting the free water content which contributes to flow [36]. The specific mechanism for the effect of packing density on yield stress is similar to that described in Section 3.2. It is worth noting that the packing density essentially reflects the result of particle physical packing, so the effect of hydration of cementitious materials cannot be taken into account. Although some studies have shown that the hydration of the binder has a significant effect on the rheological properties of CPB slurry $[54,55]$. However, both the mini slump test and the rheological test were carried out quickly after the mixing was completed. In other words, these experiments were all completed within the induction period of hydration of the binder [56]. Therefore, it is reasonable to ignore the effect of hydration of the binder in this study.

In addition, a function fitting was carried out to explore the relationship between flow spread and yield stress

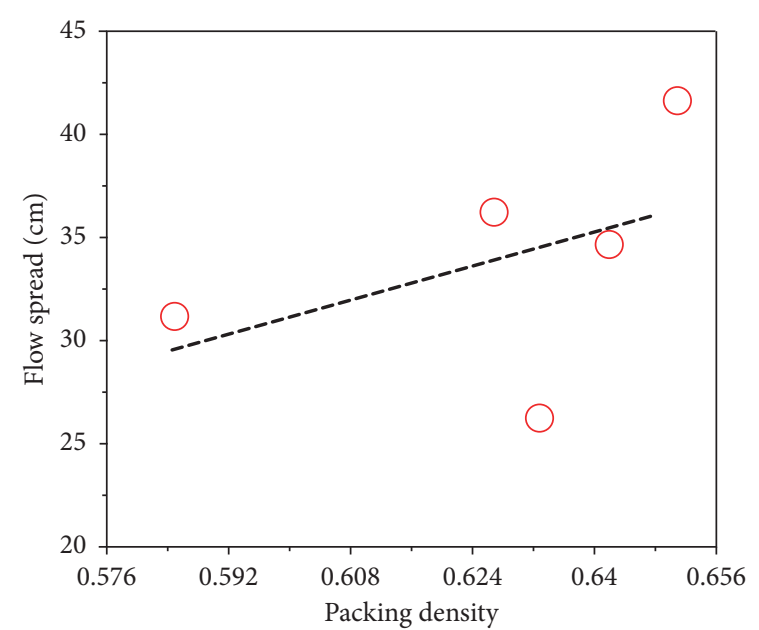

FIgURE 6: Relationship between packing density and flow spread.

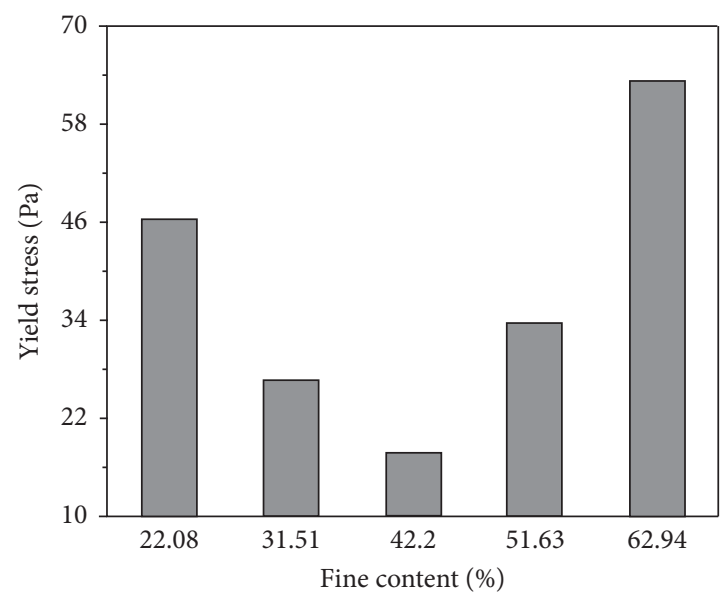

FiguRE 7: Yield stress variation with fine contents.

(Figure 8). The results show that there is an exponential relationship between flow spread and yield stress, and the correlation coefficient reaches 0.989 . Therefore, the exponential model can be used as an empirical formula to estimate the yield stress by using the mini slump test, which has a certain significance for the engineering site. Liu et al. also reached a similar conclusion [56]. However, after comparing with the model in this study, it can be found that the coefficients in the two models are greatly different. This indicates that the composition of CPB has a great influence on the coefficient of the model, so the model with stronger applicability needs to be further studied.

3.4. Effect of Tailings Fine Content on UCS. The variation of UCS of CPB with tailings fine content after 28 days curing is shown in Figure 9 (solid content is $72 \%$ ). With the increase of tailings fine content, the UCS of CPB first increases to the maximum value of $1.65 \mathrm{MPa}$ and then decreases slowly. For example, when the tailings fine content increases from $22.08 \%$ to $42.2 \%$, the strength of CPB increases by $30 \%$. However, when the tailings fine content increases from 


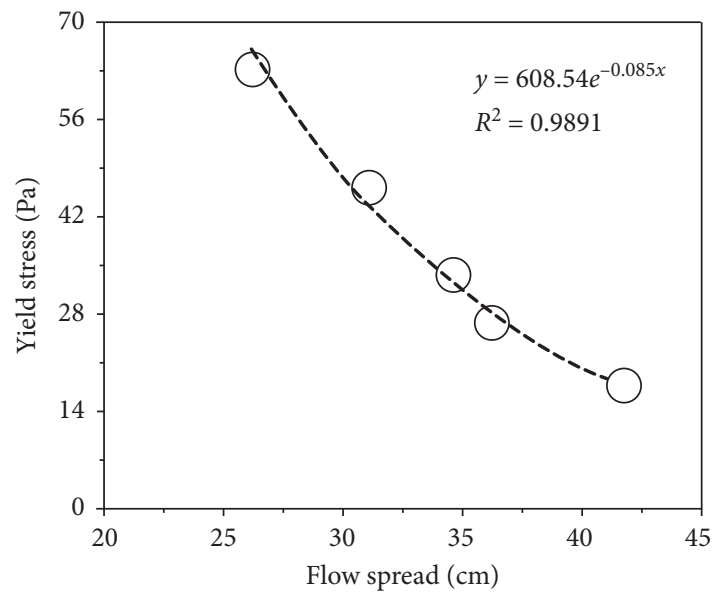

FIGURE 8: Correlation between flow spread and yield stress for fresh CPB.

$42.2 \%$ to $62.94 \%$, the corresponding strength decreases by $9.1 \%$. The variation trend of strength is consistent with that of packing density. This indicates that the packing density is an important factor affecting the strength of CPB. A fitting analysis was conducted to further analyze the relationship between strength and packing density, and the results are shown in Figure 10. As can be seen from the figure, there is a good linear relationship between strength and packing density, and the correlation coefficient reaches 0.97 . This means that the packing density of tailings can be used to predict the strength of $\mathrm{CPB}$. The mechanism by which packing density affects $\mathrm{CPB}$ strength is further analyzed in the following section.

$\mathrm{Wu}$ et al. introduced Talbot gradation theory to study the influence of grain size distribution of waste rock on the cemented waste rock backfill (CWRB), and the results showed that when the gradation Talbot index was between 0.4 and 0.6 , CWRB showed the best UCS and UPV performance [57]. Sevim and Demir used Dinger-Funk particle size distribution modulus $(q)$ to explore the influence of fly ash particle size distribution on the compressive and flexural strength of fly ash-blended cement mortars, and the results revealed that when $q$ is 0.4 , mortars yield the best mechanical properties [58]. Therefore, it is necessary to explore the quantitative relationship between tailing particle size distribution and UCS for the purpose to further understand the mechanism of tailing particle size distribution affecting CPB properties. Here, the gradation Talbot index ( $t$, obtained according to equation (6)) is used to correlate the UCS of the CPB, and the result is shown in Figure 11. The larger the $t$ value is, the coarser the tailing particles are. Therefore, with the increase of tailings fine content, $t$ value must decrease. It can be seen from Figure 11 that the UCS of CPB presents a good quadratic polynomial relationship with $t$ value (the correlation coefficient reaches 0.929$)$. When $t$ is 0.38 , the strength value of $\mathrm{CPB}$ is the maximum. In other words, when $t$ is 0.41 , the packing density of the particle system at this time is the largest, which is proved by the experimental results of tailings fine content and packing density in Section 3.1.

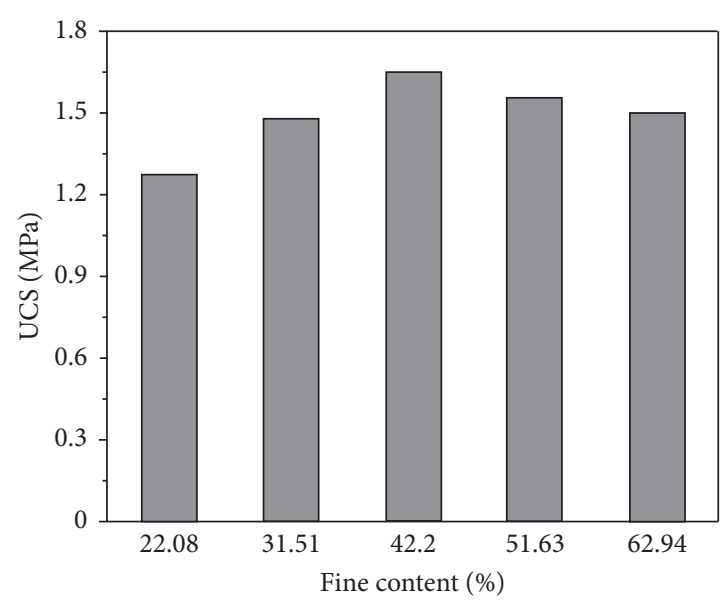

FIGURE 9: UCS variation with fine contents.

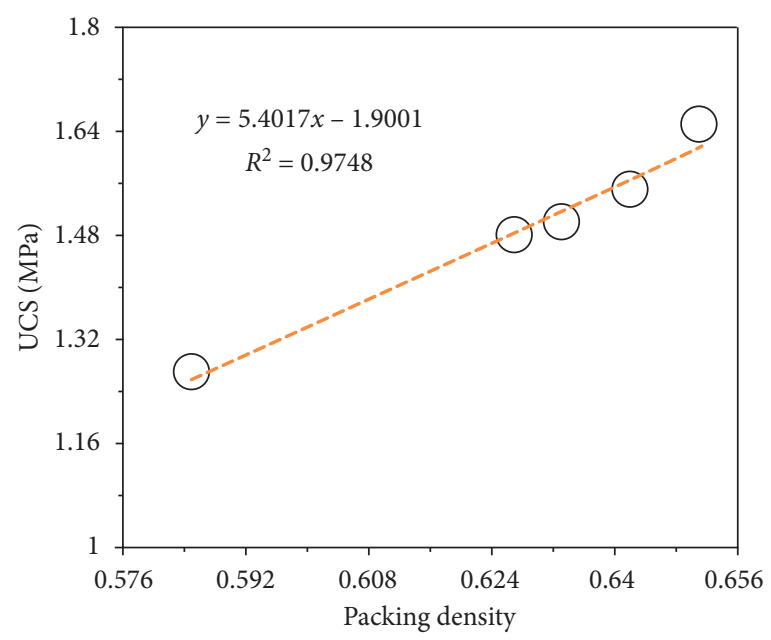

FIgURE 10: Relationship between packing density and UCS.

Furthermore, these results are consistent with the conclusions of $\mathrm{Wu}$ et al. [31,59] and Zhang et al. [60].

$$
P_{i}=100 *\left(\frac{D_{i}}{D_{\max }}\right)^{t},
$$

where $D_{i}$ is the particle size of tailings $(\mu \mathrm{m}) ; D_{\max }$ is the maximum tailings particle size $(\mu \mathrm{m}) ; P_{i}$ represents the tailing volume percentage with particle size smaller than that occupied by $D_{i}(\%) ; P_{i}$ represents the volume percentage of tailings with particle size less than $D_{i}(\%)$.

3.5. Effect of Tailings Fine Content on Pore Structure. It is well known that the strength of CPB is essentially determined by its internal microstructure [61]. Figure 12 shows the pore size distribution of $\mathrm{CPB}$ with different tailings fine contents (curing time is 28 days). It can be clearly seen from the figure that when the tailings fine content is $42.2 \%$, its pore distribution curve is at the far left, which indicates that this CPB sample has a finer pore structure. The samples with tailings fineness content of $62.94 \%$ and $22.08 \%$ have obviously poor 


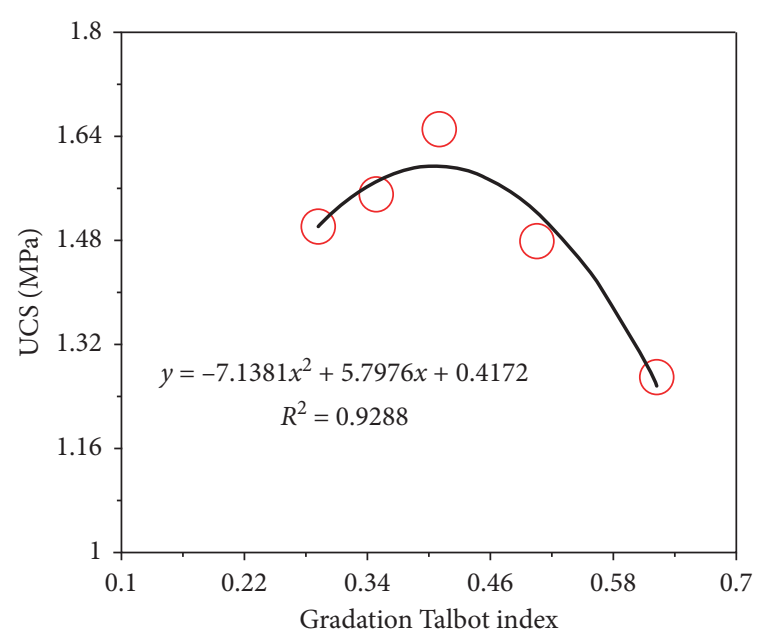

FIGURE 11: Relationship between gradation Talbot index and UCS.

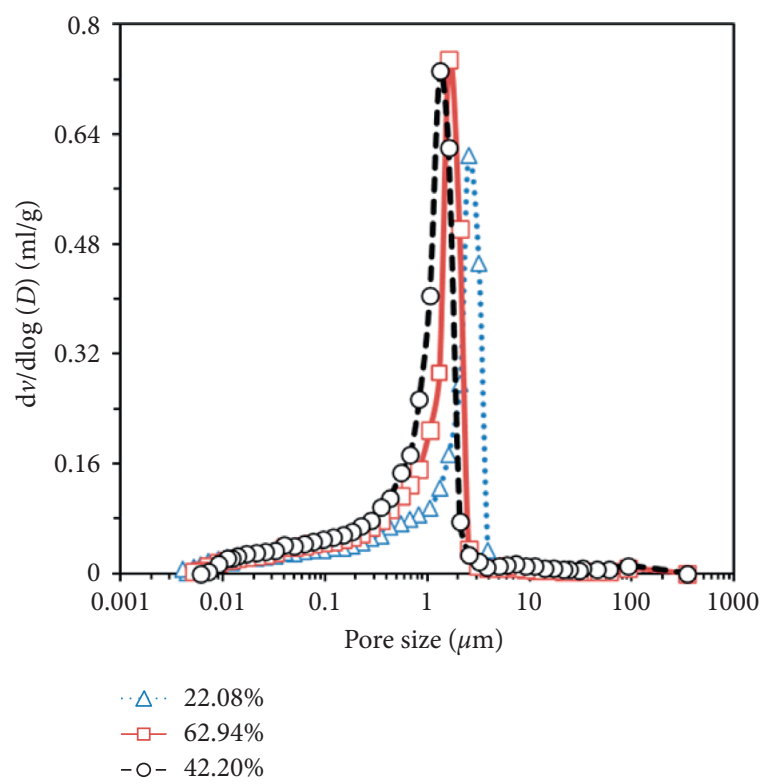

Figure 12: MIP test results under different fine contents.

pore structure, but the pore structure of the former is better than that of the latter. This is consistent with the results of packing density, indicating that the macroscopic packing density affects the strength of CPB by affecting the microscopic pores.

\section{Conclusions}

Based on the experimental results and discussion in this study, the following conclusions can be drawn:

(1) The packing density of tailings obtained by the dry packing method is less than that obtained by the wet packing method. With the increase of tailing fine content, the packing density increases first and then decreases.

(2) With the increase of tailings fine content, the flow spread of fresh CPB increases first and then decreases significantly, while the yield stress shows an opposite trend. There is an exponential relationship between flow spread and yield stress of fresh CPB. The tailings fine content mainly affects the flowability and rheological properties of the CPB slurry through the packing density, but when the fine content is high, the influence of specific surface area of tailings cannot be ignored.

(3) With the increase of tailings fine content, the UCS of $\mathrm{CPB}$ increases first and then decreases slightly. The packing density is an important factor affecting the strength of $\mathrm{CPB}$, and there is an obvious linear relationship between the packing density and the UCS of CPB. When the gradation Talbot index is 0.41 , the strength of the $\mathrm{CPB}$ reaches the maximum.

(4) The pore structure of CPB samples with different tailings fine content is obviously different. The macroscopic packing density changes the strength of $\mathrm{CPB}$ by affecting the microscopic pores.

It is worth noting that the hydration of the binder was not considered in this study, so the coupling effect of hydration of binders and packing density on CPB performances will be the focus of our future work.

\section{Data Availability}

The [DATA TYPE] data used to support the findings of this study are included within the article.

\section{Conflicts of Interest}

The authors declare that they have no conflicts of interest.

\section{Acknowledgments}

The supports of Study on Identification of Key Characteristic Variables for Stability of Chamber Group in Underground Concentrator (02-1922); Key Research and Development Project of Liaoning (2020JH1/10300005), the Fundamental Research Funds for the Central Universities (N2001024), and the Innovation Program for College Students, Northeastern University (210069) are gratefully acknowledged.

\section{References}

[1] M. Fall, T. Belem, S. Samb, and M. Benzaazoua, "Experimental characterization of the stress-strain behaviour of cemented paste backfill in compression," Journal of Materials Science, vol. 42, no. 11, pp. 3914-3922, 2007.

[2] M. Fall, M. Benzaazoua, and S. Ouellet, "Experimental characterization of the influence of tailings fineness and density on the quality of cemented paste backfill," Minerals Engineering, vol. 18, no. 1, pp. 41-44, 2005.

[3] L. Yang, W. Xu, E. Yilmaz, Q. Wang, and J. Qiu, “A combined experimental and numerical study on the triaxial and dynamic compression behavior of cemented tailings backfill," Engineering Structures.vol. 219, Article ID 110957, 2020.

[4] J. Wang, J. Fan, and P. Qin, "Pullution of aromatic compounds and elements of a coal gangue dump from Fengfeng 
Coal Mine 5, China," World Journal of Engineering, vol. 8, no. 1, pp. 15-22, 2011.

[5] Q. Hu, B. Lei, K. Ma, and T. Wang, "Analysis of surface mining subsidence laws under thick alluvial Quandian Mine," World Journal of Engineering, vol. 11, no. 3, pp. 247-256, 2014.

[6] C. Qi and A. Fourie, "Cemented paste backfill for mineral tailings management: review and future perspectives," Minerals Engineering, vol. 144, Article ID 106025, 2019.

[7] G. Wang, L. Yang, and Y. S. Zhang, "Modularized design of coal-mine paste filling station based on fuzzy theory," World Journal of Engineering, vol. 15, no. 6, pp. 743-750, 2018.

[8] Q. Chen, S. Sun, Y. Liu, C. Qi, H. Zhou, and Q. Zhang, "Experimental and numerical study on immobilization and leaching characteristics of fluoride from phosphogypsum based cemented paste backfill," International Journal of Minerals, Metallurgy and Materials, 2021.

[9] D. Wang, Q. Zhang, Q. Chen, C. Qi, Y. Feng, and C. Xiao, "Temperature variation characteristics in flocculation settlement of tailings and its mechanism," International Journal of Minerals, Metallurgy and Materials.vol. 27, no. 11, pp. 1438-1448, 2020.

[10] L. Yang, J. Qiu, H. Jiang, S. Hu, H. Li, and S. Li, "Use of cemented super-fine unclassified tailings backfill for control of subsidence," Minerals, vol. 7, no. 11, p. 216, 2017.

[11] J. Qiu, L. Yang, X. Sun, J. Xing, and S. Li, "Strength characteristics and failure mechanism of cemented super-fine unclassified tailings backfill," Minerals, vol. 7, no. 4, p. 58, 2017.

[12] A. Ghirian and M. Fall, "Coupled behavior of cemented paste backfill at early ages," Geotechnical and Geological Engineering, vol. 33, no. 5, pp. 1141-1166, 2015.

[13] G. Wang, Y. S. Zhang, L. Yang, and S. Zhang, "Paste-filling weighing control system optimization based on neural network," World Journal of Engineering, vol. 14, no. 2, pp. 155-158, 2017.

[14] M. Fall, D. Adrien, J. C. Célestin, M. Pokharel, and M. Touré, "Saturated hydraulic conductivity of cemented paste backfill," Minerals Engineering, vol. 22, no. 15, pp. 1307-1317, 2009.

[15] E. Yilmaz, M. Benzaazoua, T. Belem, and B. Bussière, "Effect of curing under pressure on compressive strength development of cemented paste backfill," Minerals Engineering, vol. 22, no. 9-10, pp. 772-785, 2009.

[16] J. Haiqiang, M. Fall, and L. Cui, "Yield stress of cemented paste backfill in sub-zero environments: experimental results," Minerals Engineering, vol. 92, pp. 141-150, 2016.

[17] J. Qiu, Z. Guo, L. Li, S. Zhang, Y. Zhao, and Z. Ma, "A hybrid artificial intelligence model for predicting the strength of foam-cemented paste backfill," IEEE Access, vol. 8, pp. 84569-84583, 2020.

[18] A. Wu, Y. Wang, H. Wang, S. Yin, and X. Miao, "Coupled effects of cement type and water quality on the properties of cemented paste backfill," International Journal of Mineral Processing, vol. 143, pp. 65-71, 2015.

[19] S. Ridha, A. I. Abd Hamid, and C. K. A. H. C. Ku, "Influence of different brine water salinity on mechanical properties of fly ash-based geopolymer cement," International Journal of Structural Integrity, vol. 9, no. 12, 2018.

[20] H. Jiang, M. Fall, E. Yilmaz, Y. Li, and L. Yang, "Effect of mineral admixtures on flow properties of fresh cemented paste backfill: assessment of time dependency and thixotropy," Powder Technology, vol. 372, pp. 258-266, 2020.

[21] K. Salhi and B. Mezghiche, "Effects of slag of blast furnace and sand of dune on durability of mortar and concrete," World Journal of Engineering, vol. 8, no. 1, pp. 23-28, 2011.
[22] M. Ozkaymak, S. Selimli, D. Kaya, and U. Uzun, "Searching the fertility potential of iron and steel industry blast furnace slag," World Journal of Engineering, vol. 13, no. 6, pp. 482-486, 2016.

[23] S. Raj, A. K. Rai, and V. G. Havanagi, "Suitability of stabilized copper slag and fly ash mix for road construction," World Journal of Engineering, vol. 15, no. 3, pp. 336-344, 2018.

[24] H. Jiang, Z. Qi, E. Yilmaz, J. Han, J. Qiu, and C. Dong, "Effectiveness of alkali-activated slag as alternative binder on workability and early age compressive strength of cemented paste backfills," Construction and Building Materials, vol. 218, pp. 689-700, 2019.

[25] F. Cihangir, B. Ercikdi, A. Kesimal, A. Turan, and H. Deveci, "Utilisation of alkali-activated blast furnace slag in paste backfill of high-sulphide mill tailings: effect of binder type and dosage," Minerals Engineering, vol. 30, pp. 33-43, 2012.

[26] S. Bechar and D. Zerrouki, "Effect of natural pozzolan on the fresh and hardened cement slurry properties for cementing oil well," World Journal of Engineering, vol. 15, no. 4, pp. 513-519, 2018.

[27] L. Zeghichi and Z. Benghazi, "Physical effects of natural pozzolana on alkali-activated slag cement," World Journal of Engineering, vol. 8, no. 2, pp. 141-146, 2011.

[28] S. Zhang, F. Ren, Z. Guo, J. Qiu, and H. Ding, "Strength and deformation behavior of cemented foam backfill in sub-zero environment," Journal of Materials Research and Technology, vol. 9, no. 4, pp. 9219-9231, 2020.

[29] D. Wu, M. Fall, and S. J. Cai, "Coupling temperature, cement hydration and rheological behaviour of fresh cemented paste backfill," Minerals Engineering, vol. 42, pp. 76-87, 2013.

[30] B. Ercikdi, F. Cihangir, A. Kesimal, H. Deveci, and İ. Alp, "Utilization of water-reducing admixtures in cemented paste backfill of sulphide-rich mill tailings," Journal of Hazardous Materials, vol. 179, no. 1-3, pp. 940-946, 2010.

[31] J. Wu, M. Feng, X. Ni, X. Mao, Z. Chen, and G. Han, “Aggregate gradation effects on dilatancy behavior and acoustic characteristic of cemented rockfill," Ultrasonics, vol. 92, pp. 79-92, 2019.

[32] P. Xiapeng, M. Fall, and S. Haruna, "Sulphate induced changes of rheological properties of cemented paste backfill," Minerals Engineering, vol. 141, Article ID 105849, 2019.

[33] W. Li and M. Fall, "Sulphate effect on the early age strength and self-desiccation of cemented paste backfill," Construction and Building Materials, vol. 106, pp. 296-304, 2016.

[34] C. Qi, A. Fourie, Q. Chen, and Q. Zhang, "A strength prediction model using artificial intelligence for recycling waste tailings as cemented paste backfill," Journal of Cleaner Production, vol. 183, pp. 566-578, 2018.

[35] X. Ke, X. Zhou, X. Wang, T. Wang, H. Hou, and M. Zhou, "Effect of tailings fineness on the pore structure development of cemented paste backfill," Construction and Building Materials, vol. 126, pp. 345-350, 2016.

[36] X. J. Deng, B. Klein, D. J. Hallbom, B. de Wit, and J. X. Zhang, "Influence of particle size on the basic and time-dependent rheological behaviors of cemented paste backfill," Journal of Materials Engineering and Performance, vol. 27, no. 7, pp. 3478-3487, 2018.

[37] H.-y. Cheng, S.-c. Wu, X.-q. Zhang, and A.-x. Wu, "Effect of particle gradation characteristics on yield stress of cemented paste backfill," International Journal of Minerals, Metallurgy and Materials, vol. 27, no. 1, pp. 10-17, 2020.

[38] J. Qiu, Z. Guo, L. Yang, H. Jiang, and Y. Zhao, "Effect of tailings fineness on flow, strength, ultrasonic and microstructure characteristics of cemented paste backfill," 
Construction and Building Materials, vol. 263, Article ID 120645, 2020.

[39] J. Qiu, Z. Guo, L. Yang, H. Jiang, and Y. Zhao, "Effects of packing density and water film thickness on the fluidity behaviour of cemented paste backfill," Powder Technology, vol. 359, pp. 27-35, 2020.

[40] H. H. C. Wong and A. K. H. Kwan, "Packing density of cementitious materials: Part 1-measurement using a wet packing method," Materials and Structures, vol. 41, no. 4, pp. 689-701, 2008.

[41] Z. Guo, J. Qiu, H. Jiang, J. Xing, X. Sun, and Z. Ma, "Flowability of ultrafine-tailings cemented paste backfill incorporating superplasticizer: insight from water film thickness theory," Powder Technology, vol. 381, pp. 509-517, 2021.

[42] M. Zhao, X. Zhang, and Y. Zhang, "Effect of free water on the flowability of cement paste with chemical or mineral admixtures," Construction and Building Materials, vol. 111, pp. 571-579, 2016.

[43] B. A. Kounakoff, L. Hanzic, and J. C. M. Ho, "Limestone and silica fume to improve concurrent flowability-segregation limits of concrete," Magazine of Concrete Research, vol. 69, no. 23, pp. 1189-1202, 2017.

[44] Z. Zhang, Y. Li, L. Ren, Z. Guo, H. Jiang, and N. Liu, "Evaluation of rheological parameters of slag-based paste backfill with superplasticizer," Advances in Materials Science and Engineering, vol. 2021, Article ID 6673033, 11 pages, 2021.

[45] S. Ma, Y. Qian, and S. Kawashima, "Experimental and modeling study on the non-linear structural build-up of fresh cement pastes incorporating viscosity modifying admixtures," Cement and Concrete Research, vol. 108, pp. 1-9, 2018.

[46] K. P. Singh, A. Kumar, and D. R. Kaushal, "Pressure drop calculation for fly ash slurry using rheological model," World Journal of Engineering, vol. 16, no. 6, pp. 751-767, 2019.

[47] A. K. H. Kwan, L. G. Li, and W. W. S. Fung, "Wet packing of blended fine and coarse aggregate," Materials and Structures, vol. 45, no. 6, pp. 817-828, 2012.

[48] A. K. H. Kwan and H. H. C. Wong, "Packing density of cementitious materials: Part 2-packing and flow of OPC + PFA + CSF," Materials and Structures, vol. 41, no. 4, pp. 773-784, 2008

[49] H. Ye, X. Gao, R. Wang, and H. Wang, "Relationship among particle characteristic, water film thickness and flowability of fresh paste containing different mineral admixtures," Construction and Building Materials, vol. 153, pp. 193-201, 2017.

[50] A. K. H. Kwan, K. W. Chan, and V. Wong, "A 3-parameter particle packing model incorporating the wedging effect," Powder Technology, vol. 237, pp. 172-179, 2013.

[51] A. K. H. Kwan and W. W. S. Fung, "Packing density measurement and modelling of fine aggregate and mortar," Cement and Concrete Composites, vol. 31, no. 6, pp. 349-357, 2009.

[52] W. Xu, M. Tian, and Q. Li, “Time-dependent rheological properties and mechanical performance of fresh cemented tailings backfill containing flocculants," Minerals Engineering, vol. 145, Article ID 106064, 2020.

[53] A. K. H. Kwan and L. G. Li, "Combined effects of water film, paste film and mortar film thicknesses on fresh properties of concrete," Construction and Building Materials, vol. 50, pp. 598-608, 2014.

[54] S. Haruna and M. Fall, "Time- and temperature-dependent rheological properties of cemented paste backfill that contains superplasticizer," Powder Technology, vol. 360, pp. 731-740, 2020.

[55] W. Xu, W. Chen, M. Tian, and L. Guo, "Effect of temperature on time-dependent rheological and compressive strength of fresh cemented paste backfill containing flocculants," Construction and Building Materials, vol. 267, Article ID 121038, 2021.

[56] H. Liu, X Sun, H Du et al., "Effects and threshold of water film thickness on multi-mineral cement paste," Cement and Concrete Composites.vol. 112, Article ID 103677, 2020.

[57] J. Wu, H. Jing, Q. Yin, B. Meng, and G. Han, "Strength and ultrasonic properties of cemented waste rock backfill considering confining pressure, dosage and particle size effects," Construction and Building Materials.vol. 242, Article ID 118132, 2020.

[58] Ö. Sevim and İ. Demir, "Optimization of fly ash particle size distribution for cementitious systems with high compactness," Construction and Building Materials, vol. 195, pp. 104-114, 2019.

[59] J. Wu, M. Feng, J. Xu, P. Qiu, Y. Wang, and G. Han, "Particle size distribution of cemented rockfill effects on strata stability in filling mining," Minerals, vol. 8, no. 9, p. 407, 2018.

[60] T. Zhang, Q. Yu, J. Wei, and P. Zhang, "A new gap-graded particle size distribution and resulting consequences on properties of blended cement," Cement and Concrete Composites, vol. 33, no. 5, pp. 543-550, 2011.

[61] E. Yilmaz, T. Belem, B. Bussière, and M. Benzaazoua, "Relationships between microstructural properties and compressive strength of consolidated and unconsolidated cemented paste backfills," Cement and Concrete Composites, vol. 33, no. 6, pp. 702-715, 2011. 